\title{
Synergistic combination of YS-1 and adriamycin inhibits human renal cancer through ERK1/2 signaling pathway in vitro and in vivo
}

\author{
XIAOWEN YU ${ }^{1}$, QINGQING YANG ${ }^{2}$, SENSEN LIN ${ }^{1}$, SHENGTAO YUAN $^{1}$ and LI SUN ${ }^{2}$ \\ ${ }^{1}$ Jiangsu Center for Pharmacodynamics Research and Evaluation, China Pharmaceutical University; \\ ${ }^{2}$ Jiangsu Key Laboratory of Drug Screening, China Pharmaceutical University, Nanjing, Jiangsu 210009, P.R. China
}

Received July 2, 2016; Accepted November 25, 2016

DOI: $10.3892 /$ or.2017.5373

\begin{abstract}
Adriamycin (ADM) is a principal drug for the treatment of renal cell cancer (RCC). Due to its limited response and high renal and cardiac toxicity, synergistic effects of ADM in combination with other drugs have been widely researched. In this study, we found the combination between YS-1 and ADM, performed higher anticancer activity on 786-O human RCC cells in vitro and in vivo, than that reported on its antiangiogenesis effect compared with monotherapy of ADM. Our data showed that when combined with ADM, YS-1 promoted the sensitivity of 786-O cells to ADM. The combination of YS-1 and ADM also inhibited cell proliferation, but without affecting cell apoptosis. We found that ADM monotherapy treatment notably upregulated the activity of extracellular signal-regulated kinase ERK1 and ERK2 (ERK1/2), but when combined with YS-1, the p-ERK1/2 level was reduced; then inhibited the Ras/Raf/MEK pathway. Additionally, the synergistic effects on cell cycle arrest inhibition were eliminated when ERK1/2 was silenced using siRNA. Our combination therapy of YS-1 with ADM showed the strongest antitumor effects in vivo (inhibition ratio: $5 \mathrm{mg} / \mathrm{kg}$ YS-1 combined with $1 \mathrm{mg} / \mathrm{kg}$ ADM, 68.19\%) in comparison with individual effects (inhibition ratio: $5 \mathrm{mg} / \mathrm{kg}$ YS $-1,30.07 \% ; 1 \mathrm{mg} / \mathrm{kg}$ ADM, $50.42 \%$ ). Collectively, these findings indicated that YS-1 did not only enhance the ability of ADM to inhibit tumor proliferation, but also reduce the renal toxicity to protect the normal renal tissues.
\end{abstract}

Correspondence to: Dr Shengtao Yuan, Jiangsu Center for Pharmacodynamics Research and Evaluation, China Pharmaceutical University, 24 Tongjiaxiang, Nanjing, Jiangsu 210009, P.R. China E-mail: yuanst@cpu.edu.cn

Dr Li Sun, Jiangsu Key Laboratory of Drug Screening, China Pharmaceutical University, 24 Tongjiaxiang, Nanjing, Jiangsu 210009, P.R. China

E-mail: sunli@cpu.edu.cn

Key words: synergistic combination, YS-1, adriamycin, human renal cancer, ERK pathway

\section{Introduction}

It is well-known that renal cell carcinoma (RCC) is a highrisk and high-mortality cancer and is notoriously resistant to traditional chemotherapies and radiotherapies (1), marked by adverse tumor biology and its low CSS ranking among urological malignancies (2). RCC patients either receive surgery or chemoradiotherapy, have poor prognosis and low five-year survival rate $(3,4)$. Because of the outcomes of chemotherapy, radiotherapy and hormone therapy are unsatisfactory, it is necessary to develop an effective adjuvant therapy.

Adriamycin (ADM), a kind of antitumor antibiotic, inhibits the synthesis of DNA and RNA, has strong cytotoxicity (5) and induces toxicity through oxidative stress (6). In clinic, ADM has been used for sarcomatoid-type tumors, including RCC $(7,8)$; however, the chronic toxicity and acute toxicity of ADM limit its clinical application $(9,10)$. YS-1, a recombinant human 433 protein, not only has been confirmed to have antiangiogenesis and antitumor effects, in vitro and in vivo (11); but also showed potential antitumor properties for primary and metastatic solid tumors. In our previous study, YS-1 could directly inhibited angiogenesis through Dll4-Notch1 signal transduction pathway (12), and caused renal toxicity mainly by the activation of ERK1/2 in kidney cells (13). Thus, inhibiting the effects of ADM on ERK1/2 pathway may be a key mechanism to improve the anticancer effect of ADM. According to our previous research, YS-1 might inhibit ERK1/2 activation through affecting the Notch1 pathway. Taking advantage of combination therapies (i.e., avoiding the risk of the development of resistance, increasing the effectiveness of the therapy, and the effectiveness of clinical combination therapies with ADM), we designed YS-1 combined with ADM, to reduce the expression of $\mathrm{p}$-ERK $1 / 2$ and increase the effectiveness of ADM therapy for RCCs.

The ERK1/2 cascade regulates a variety of cellular processes by phosphorylating multiple target proteins (14). The outcome of its activation ranges from stimulation of cell survival and proliferation to triggering tumor suppressor responses such as cell differentiation, cell senescence, and apoptosis (15). Recent studies have shown that inhibition of ERK1/2 can effectively reverse the multidrug resistance of prostate cancer, gastric cancer, and cancer of the blood system (16-18). The signaling 
via the ERK cascade is mediated by sequential phosphorylation and activation of protein kinases in the different tiers of the cascade, and the main core phosphorylation chain of the cascade includes Raf kinases, MEK1/2, ERK1/2 (ERKs) and RSKs. The Ras/Raf/MEK/ERK pathway has been reported to be activated in over $50 \%$ of acute myelogenous leukemia and acute lymphocytic leukemia and is also frequently activated in other cancer types (e.g., breast and prostate cancers). Importantly, this increased expression is associated with a poor prognosis (19). The Ras/Raf/MEK/ERK interacts with each other to regulate growth and in some cases tumorigenesis, and it is commonly thought to have anti-apoptotic and drug resistance effects on cells $(20,21)$.

In this study, we assessed the antitumor activity of ADM alone and in combination with YS-1 on RCCs. We also identified the optimal dose of YS-1 which can decrease p-ERK1/2 expression without causing toxicity. We propose that inhibition of the ERK1/2 activation by YS-1 may be a promising therapeutic target for enhancing the sensitivity of cancer cells to ADM. These findings highlighted the possibility of using such natural, safe, relatively inexpensive compounds as potential adjunct treatment in improving the overall treatment response of patients with RCC.

\section{Materials and methods}

Cell culture and siRNA. Human cancer (95D, SGC-7901, BEL-7402, MDA-MB-435 and 786-O) cell lines were purchased from the Shanghai Institute of Life Science, Chinese Academy of Sciences. BEL-7402 cells were maintained in DMEM with $10 \%$ fetal bovine serum (FBS, Gibco) and antibiotics (100 U/ml penicillin, and $100 \mathrm{mg} / \mathrm{ml}$ streptomycin). The other cells were grown in RMPI-1640 with 10\% FBS and antibiotics (100 U/ml penicillin, and $100 \mathrm{mg} / \mathrm{ml}$ streptomycin). Cells were incubated in a humidified atmosphere with $5 \%$ $\mathrm{CO}_{2}$ at $37^{\circ} \mathrm{C}$. ERK1/2 siRNA was purchased from Shanghai GenePharma Co., Ltd. (Shanghai, China). Lipofectamine 2000 reagent was obtained from Invitrogen (Shanghai, China).

Cell growth inhibition assay. Cells were seeded in 96-well plates in $180 \mu \mathrm{l}$ of medium and incubated for $12 \mathrm{~h}$. These cells were then cultured in the presence of YS-1, ADM individually as well in combination for $72 \mathrm{~h}$. Afterwards, $5 \mathrm{mg} / \mathrm{ml} \mathrm{MTT}$ solution $\left(20 \mu \mathrm{l} /\right.$ well) was added and cultured in $5 \% \mathrm{CO}_{2}$ incubator at $37^{\circ} \mathrm{C}$ for $4 \mathrm{~h}$, then the supernatant was discarded and DMSO was added $(150 \mu \mathrm{l} /$ well $)$. The suspension was placed on a micro-vibrator for $5 \mathrm{~min}$ and the absorbance was measured at $570 \mathrm{~nm}$ using a Universal Microplate Reader (EL800; Bio-Tek Instruments Inc.). Experiments were performed in triplicate in a parallel manner for each concentration and the results are presented as the mean \pm SD. The inhibitory ratio was calculated by the following formula: inhibitory ratio $(\%)=(1-$ average absorbance of treated group/average absorbance of control group) $\mathrm{x} 100$.

Colony formation assays. The 786-O cells were seeded in a dish $(100 \mathrm{~mm}$ x $20 \mathrm{~mm})$ at a density of 300 cells per dish and cultured in the presence of YS-1, ADM individually as well in combination for two weeks. At the end of the incubation, the cells were fixed with $4 \%$ paraformaldehyde and stained with Giemsa. Megascopic cell colonies were counted using Image-Pro Plus 6.0 software (Media Cybernetics, Bethesda, MD, USA). Each measurement was performed in triplicate and the experiments were conducted at least three times. The clone formation rate was calculated by the following formula: clone formation rate $(\%)=$ (number of colonies cells $/$ number of vaccination cells) $\mathrm{x} 100$.

Cell cycle analysis. The 786-O cells $\left(1 \times 10^{6}\right)$ were seeded into dish $(100 \mathrm{~mm} \times 20 \mathrm{~mm})$ and incubated overnight, and then cultured in the presence of YS-1, ADM individually as well in combination for $6 \mathrm{~h}$. Next, the cells were harvested, washed with cold PBS, and then fixed with $70 \%$ cold ethanol at $4^{\circ} \mathrm{C}$ overnight. After being washed twice with cold PBS, fixed cells were resuspended with $100 \mu \mathrm{g} / \mathrm{ml}$ RNase, incubated with $50 \mu \mathrm{g} / \mathrm{ml} \mathrm{PI}$ at $37^{\circ} \mathrm{C}$ for $30 \mathrm{~min}$ in the dark. Data acquisition and analysis were performed in Becton Dickinson FACS Calibur flow cytometer using Cell Quest software (Franklin Lakes, NJ, USA).

Wound closure assay. The 786-O cells were cultured to confluence or near confluence ( $>90 \%)$ in a 6-well dish. A sterile $10 \mu \mathrm{l}$ pipette tip was used to scratch a cross-shaped wound through the cells. Cells were rinsed with PBS, and were cultured in the presence of YS-1, ADM individually and in combination. Wounds were imaged at 0 , and $6 \mathrm{~h}$ under a microscope with an attached camera. The TScratch program (Computational Science and Engineering Laboratory, Zurich, Switzerland) (22) was used to measure the open areas and analyze the data.

Migration assay. Cells $\left(5 \times 10^{4}\right)$ were suspended in $200 \mu 1$ serum-free RMPI-1640 medium and seeded into the upper chamber of each insert of Transwell (Millipore). Then, $700 \mu \mathrm{l}$ of RMPI-1640 containing $10 \%$ FBS was added to a 24-well plate. After incubation at $37^{\circ} \mathrm{C}$ for $6 \mathrm{~h}$, the cells that migrated were fixed and stained for $30 \mathrm{~min}$ in a $0.1 \%$ Crystal Violet solution in PBS. The migrated cells were quantified by manual counting by using Image-Pro Plus 6.0 software (Media Cybernetics), and five randomly chosen fields were analyzed for each group.

Annexin V/PI double staining. Cells were incubated for $6 \mathrm{~h}$ with YS-1, ADM separately or in combination. Apoptotic cells were identified by the Annexin V-FITC Apoptosis Detection kit (Vazyme) in accordance with the manufacturer's instructions. Flow cytometric analysis was performed immediately after supravital staining.

Cell transfection. Cells were transfected with ERK1/2 siRNA using Lipofectamine 2000 (Invitrogen) according to the manufacturer's protocol. The transfection medium (OptiMEM; Gibco) was replaced with complete medium $12 \mathrm{~h}$ after transfection, and the cells were incubated for the indicated times.

Western blot analysis. Cells were treated with YS-1 alone, ADM alone or combination both for $6 \mathrm{~h}$. As previously described (23), then cellular protein extraction and Western blot analysis were performed. All first antibodies were purchased from Cell Signaling Technology, Inc. Horseradish peroxidase (HRP) linked anti-mouse immunoglobulin G 


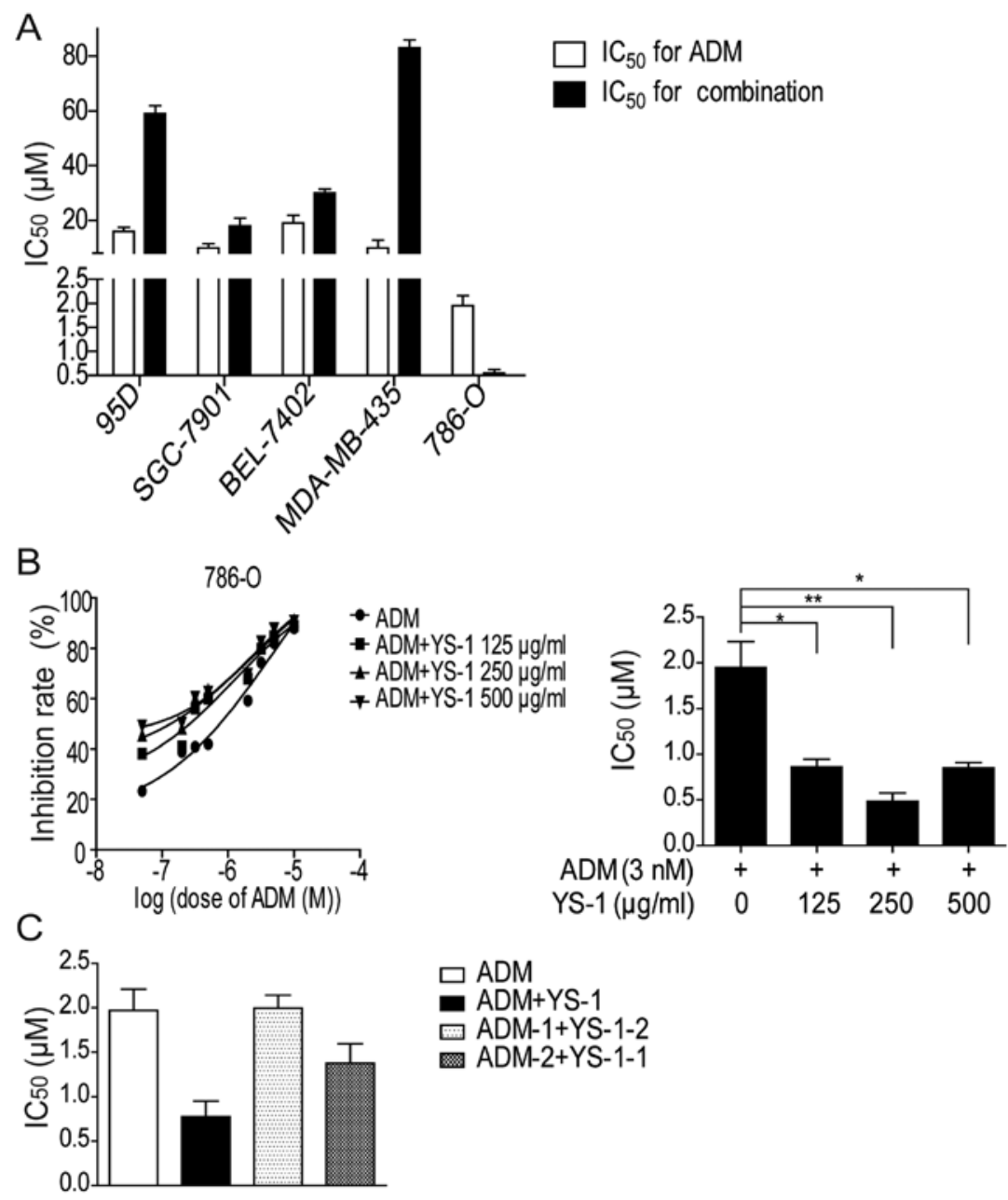

Figure 1. YS-1 combined with ADM had a synergistic anticancer effect on cell death in RCC. (A) MTT assay was used to measure the inhibitory effect of YS-1 combined with ADM on the survival of different cancer cell lines: 95D, SGC-7901, BEL-7402, MDA-MB-435, 786-O. (B) MTT assay was used to determine the appropriate concentration of YS-1 when combined with ADM (3 nM). (C) The inhibitory effect of the different drug delivery order of ADM (3 nM). Statistical analysis was performed using one-way ANOVA followed by Bonferroni's multiple comparison test, $\mathrm{P}<0.05 ;{ }^{* *} \mathrm{P}<0.01$, for B statistical analysis was performed using at least three independent replicates.

(Sigma) and anti-rabbit immunoglobulins G (CST) were used as the secondary antibodies. Different protein bands were made visible by enhanced chemiluminescence reagents (Amersham Pharmacia Biotech).

Quantitative real-time PCR. Total RNA was extracted using TRIzol reagent (Invitrogen). Complimentary DNA (cDNA) was synthesized with the Prime-Script RT reagent kit (Takara). The mRNA level was measured with the SYBR Green master mix (Vazyme). The amount of mRNA for each gene was standardized with internal control (GAPDH mRNA). Each treatment group was compared with the control group to show the relative mRNA level. The gene-specific primer pairs were as follows: GAPDH (F) 5'-GGTGGTCTCCTCTGACTTCA ACA-3', GAPDH (R) 5'-GTTGCTGTAGCCAAATTCGT TGT-3'; hERK1 (F) 5'-CATGAGAATGTCATCGGCATCC-3', hERK1 (R) 5'-CCATCAGGTCCTGCACAATGTAG-3'; hERK2 (F) 5'-GACATTATTCGAGCACCAACCATC-3', hERK2 (R) 5'-GAGGTGTTGTGTCTTCAAGAGCTTG-3'.

In vivo tumorigenicity. Female athymic BALB/c nude mice (5-6 weeks old) with body weight from 18 to $22 \mathrm{~g}$ were supplied by the Shanghai Institute of Materia Medica, Chinese Academy of Sciences. 786-O cells were collected in serum-free RMPI1640 medium and cell suspension $\left(10^{7}\right.$ cells $\left./ 100 \mu \mathrm{l}\right)$, then cell suspension was injected subcutaneously into mice in one flank $(\mathrm{n}=6)$. Animal care and surgery protocols were approved by Animal Care Committees of China Pharmaceutical University. All animals were treated appropriately and used in a scientifically valid and ethical manner.

Statistical analysis. All of the results are presented as mean \pm SD from triplicate experiments which were performed in a parallel manner unless otherwise indicated. Statistically significant differences (one-way ANOVAs followed by Bonferroni's multiple comparison test) were determined using GraphPad Prism 6 software. $\mathrm{P}<0.05$ was considered significant, and $\mathrm{P}<0.01$ and $\mathrm{P}<0.001$ were considered highly significant.

\section{Results}

YS-1 combined with ADM has a synergistic anticancer effect on cell death in RCCs. We measured the inhibitory effect of YS-1 combined with ADM on the survival of different cancer 
A
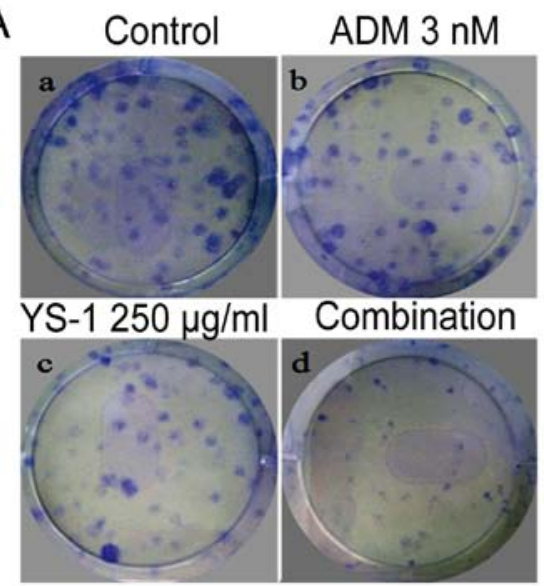

C Control

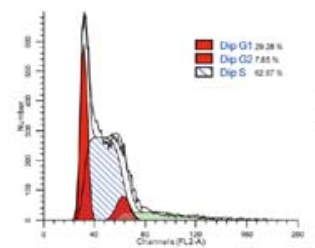

YS-1 $250 \mu \mathrm{g} / \mathrm{ml}$

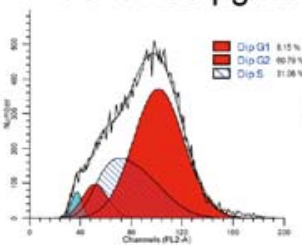

ADM 3 nM

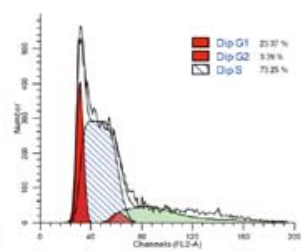

Combination

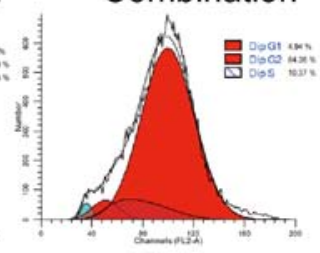

B

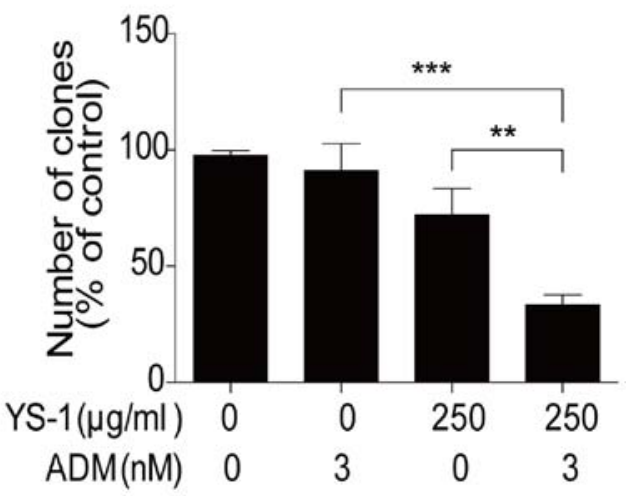

D

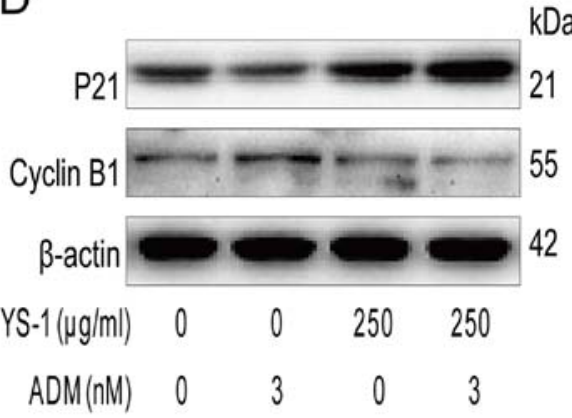

Figure 2. YS-1 combined with ADM promotes the anti-proliferative activity in 786-O cells. (A and B) The combination treatment of YS-1 and ADM could inhibit clone formation activity of 786-O cells. (C) The combination treatment of YS-1 and ADM induced G2/M cell cycle arrest of 786-O cells. (D) The G2/M cell cycle arrest related proteins were detected by western blot analysis. Statistical analysis was performed using one-way ANOVA followed by Bonferroni's multiple comparison test, ${ }^{* *} \mathrm{P}<0.01 ;{ }^{* * * *} \mathrm{P}<0.001$, for $\mathrm{B}, \mathrm{G}$ statistical analysis was performed using at least three independent replicates.

A
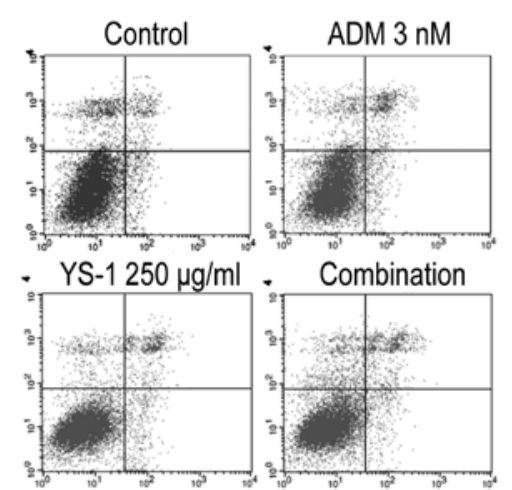

C

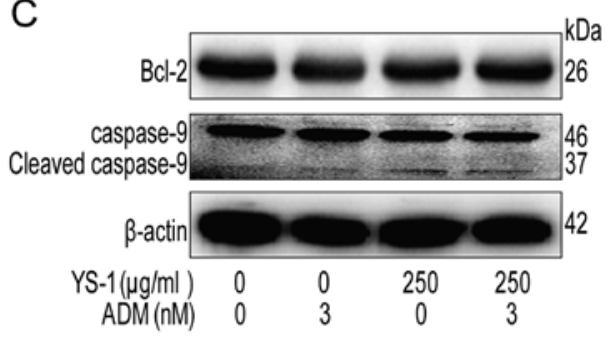

B

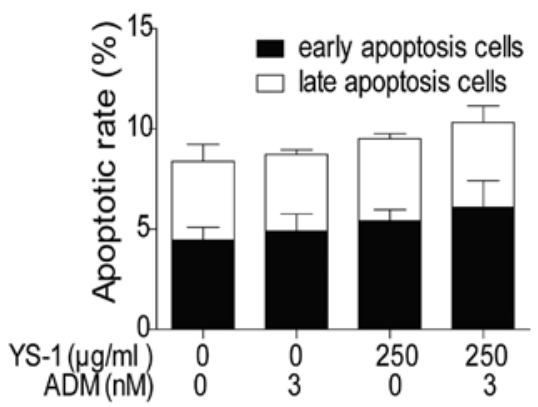

D

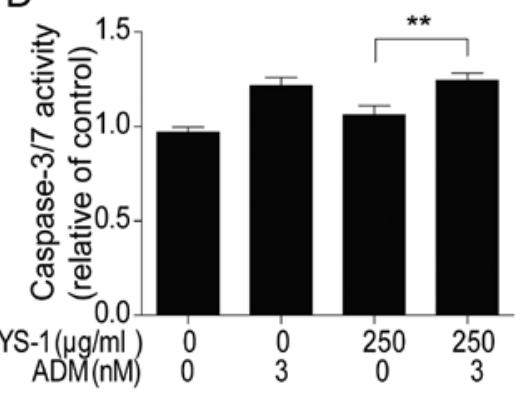

Figure 3. Synergistic anticancer effect of YS-1 combined with ADM did not induce pro-apoptotic activity in 786-O cells. (A and B) The early apoptosis was assessed by Annexin-V/PI staining in 786-O cells. (C) The apoptosis related proteins were assessed by western blot analysis in 786-O cells. (D) The activity of caspase-3/7 was determined by Apo-One ${ }^{\circledR}$ homogeneous Caspase-3/7 assay. Statistical analysis was performed using one-way ANOVA followed by Bonferroni's multiple comparison test, ${ }^{* *} \mathrm{P}<0.01$. 
A

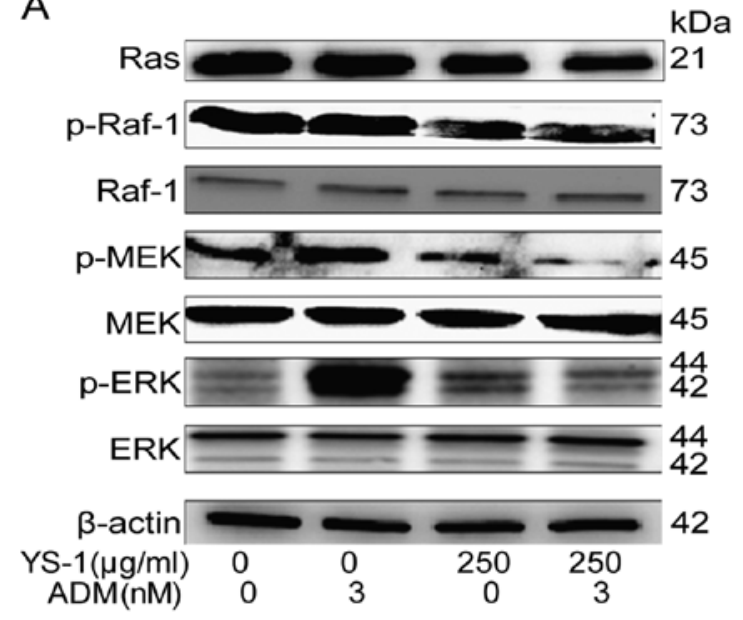

B

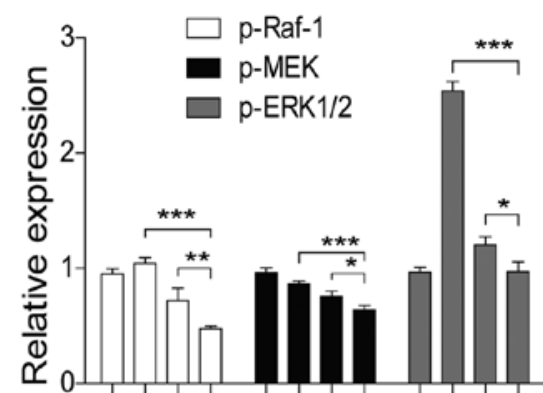

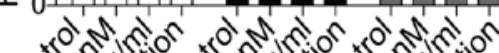

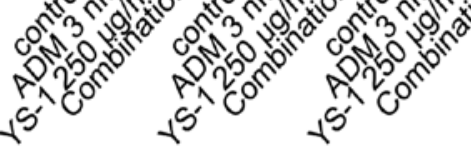

C
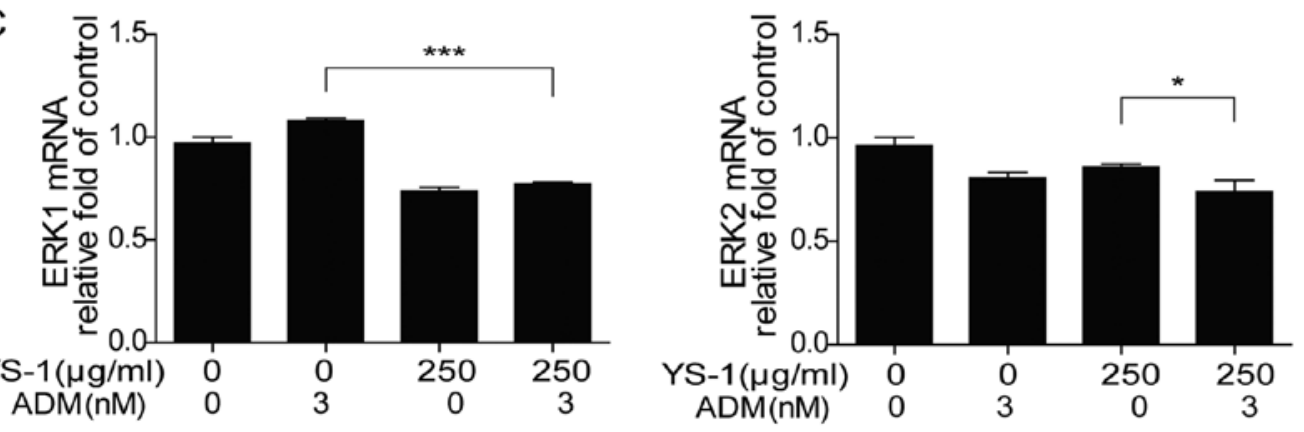

$\mathrm{D}$

\begin{tabular}{lll}
\multicolumn{3}{c}{$Y \mathrm{YS}_{-1}(\mu \mathrm{g} / \mathrm{ml})$} \\
\cline { 2 - 4 } & $125 \quad 250 \quad 500$
\end{tabular}
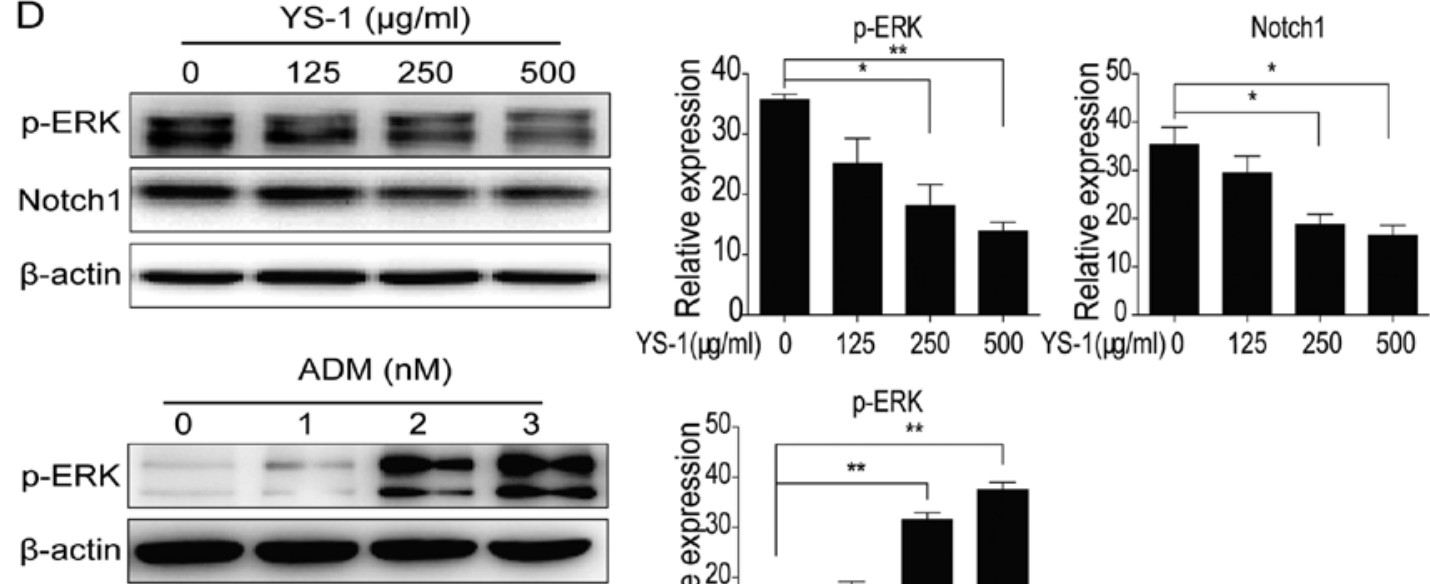

YS-1 ( $\mathrm{\mu g} / \mathrm{ml}) \quad 0 \quad 125 \quad 250 \quad 500$ YS-1 $(\mu \mathrm{g} / \mathrm{ml}) 0 \quad 125 \quad 250 \quad 500$

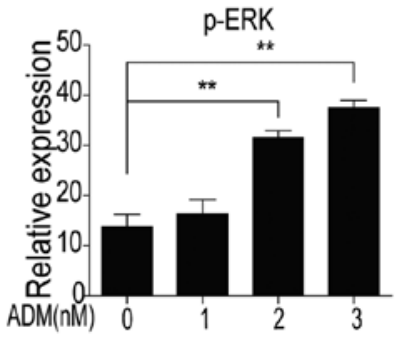

Figure 4. YS-1 combined with ADM down-regulates Ras/Raf/MEK/ERK1/2 pathway. (A and B) The combination treatment significantly reduced the Ras/ Raf/MEK/ERK1/2 pathway. (C) The ERK1 and ERK2 mRNA levels were detected by QPCR analysis. (D) The 786-O cells were treated with YS-1 (125, 250, $500 \mu \mathrm{g} / \mathrm{ml})$, or ADM $(1,2,3 \mathrm{nM})$ for $6 \mathrm{~h}$, the levels of p-ERK1/2 and Notch1 were checked by western blot analysis. Statistical analysis was performed using one-way ANOVA followed by Bonferroni's multiple comparison test, ${ }^{*} \mathrm{P}<0.05 ;{ }^{* *} \mathrm{P}<0.01 ;{ }^{* * *} \mathrm{P}<0.001$.

cell lines: 95D, SGC-7901, BEL-7402, MDA-MB-435, 786-O. After $72 \mathrm{~h}$ of treatment, we found YS-1 combined with ADM only exhibited a synergistic inhibitory effect on the survival of 786-O cells (Fig. 1A).

In order to determine the optimum concentration of YS-1 when combined with ADM, 786-O cells were treated with ADM and YS-1 $(125,250$, and $500 \mu \mathrm{g} / \mathrm{ml}$, respectively) for $72 \mathrm{~h}$, we found that when combining ADM with $250 \mu \mathrm{g} / \mathrm{ml}$ YS-1, the $\mathrm{IC}_{50}$ value reduced most markedly (Fig. 1B). Next, we investigated the inhibitory effect of the different drug delivery order of $3 \mathrm{nM}$ ADM with $250 \mu \mathrm{g} / \mathrm{ml} \mathrm{YS}-1$ on $786-\mathrm{O}$ cells, as shown in Fig. 1C, only when YS-1 and ADM were added simultaneously, the $\mathrm{IC}_{50}$ value reduced most significantly. These findings clearly showed that $250 \mu \mathrm{g} / \mathrm{ml}$ YS -1 combined with $3 \mathrm{nM}$ ADM exhibited a synergistic inhibitory effect on the survival of 786-O cells.

YS-1 combined with ADM promote anti-proliferative activity in 786-O cells. To investigate the mechanism of the combined treatment on the survival of 786-O cells, we measured the 
A
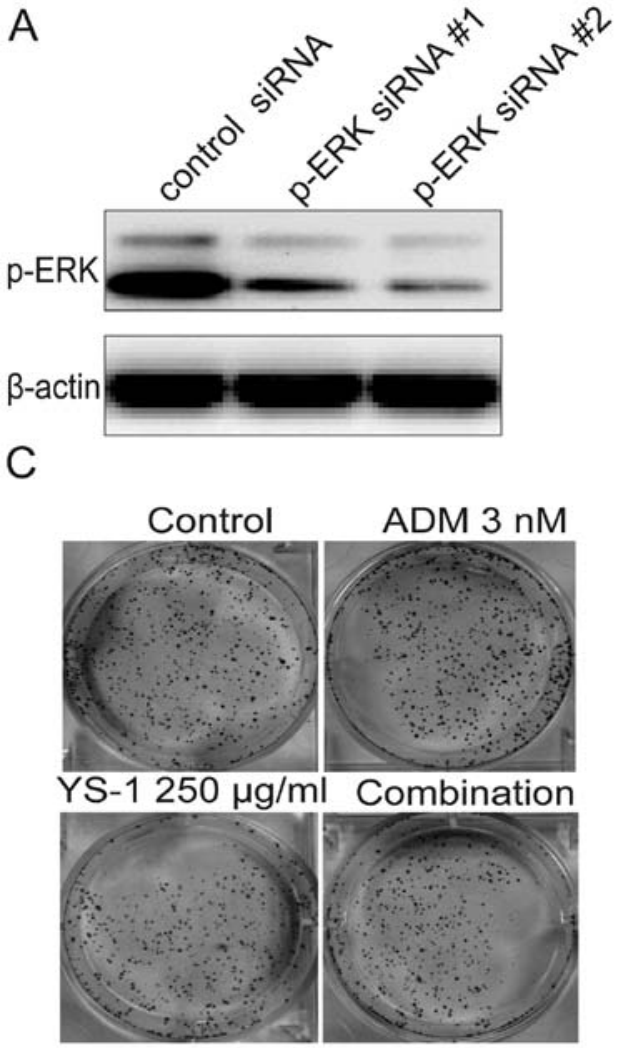

B

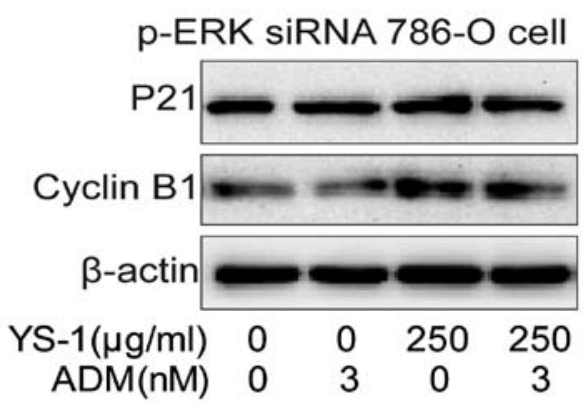

$\mathrm{D}$

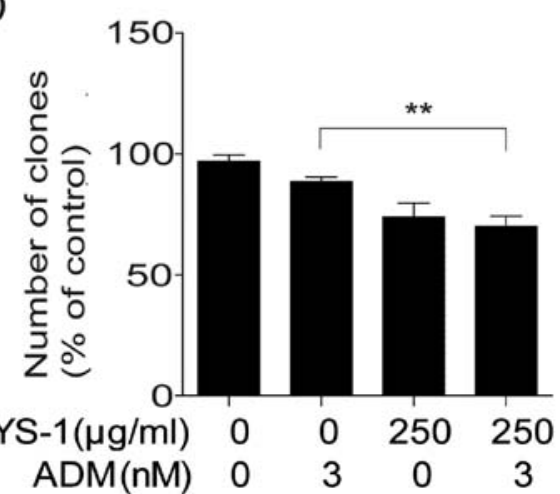

Figure 5. YS-1 combined with ADM play synergistic effects through p-ERK1/2 inhibition. (A) The ERK1/2 and p-ERK1/2 protein levels were examined by western blot analysis in 786-O cells transfected with ERK1/2 siRNA. (B) The ERK1/2 silenced 786-O cells were used to determine the effects of p-ERK1/2 on the combination anti-proliferation activity through cell cycle related protein assay. (C and D) The effects of the combination treatment on the 786-O cell clone formation activity when ERK1/2 was silenced. Statistical analysis was performed using one-way ANOVA followed by Bonferroni's multiple comparison test, ${ }^{* *} \mathrm{P}<0.01$.

effect of combination treatment on anti-proliferative activity. As shown in Fig. 2A and B, the combination treatment group inhibited the clone formation of 786-O cells significantly. Moreover, the combination group induced apparent G2/M cell cycle arrest in 786-O cells as assessed by flow analysis (Fig. 2C). Then we measured the levels of proteins involved in the G2/M cell cycle arrest pathway. The combination treatment increased the expression of $\mathrm{P} 21$ and reduced the expression of cyclin B1 (Fig. 2D). These findings clearly showed YS-1 combined with ADM promoted the anti-proliferative activity in $786-\mathrm{O}$ cells.

Synergistic anticancer effect of YS-1 combined with ADM did not increase the pro-apoptotic activity in 786-O cells. Apoptosis is an important mechanism contributing to the cell survival reduction (24), so in our further investigation, we measured the effect of the combined treatment on the pro-apoptotic activity. As shown in Fig. 3A and B, after $6 \mathrm{~h}$ treatment, compared with the monotherapy group, the combtherapy group could not show any synergistic pro-apoptotic effect, by flow analysis in 786-O cells. After that, we analysed the protein levels of Bcl-2 and the cleaved level of caspase- 9 by western blot analysis in 786-O cells, and found that the combination group did not downregulate $\mathrm{Bcl}-2$ or upregulate cleaved caspase-9 (Fig. 3C) compared with ADM monotherapy treatment group. Furthermore, the activity of caspase-3/7 was consistent with the results of flow analysis and western analysis (Fig. 3D). These finding clearly showed YS-1 combined with ADM could not induce pro-apoptotic activity in 786-O cells.

YS-1 combined with ADM regulate anti-proliferative activity via down-regulating Ras/Raf/MEK/ERK1/2 pathway. Ras/ $\mathrm{Raf} / \mathrm{MEK} / \mathrm{ERK} 1 / 2$ pathway could influence cell growth and drug resistance (19). Recently, research showed that the renal toxicity of ADM was mainly induced by the activation of ERK1/2 signaling pathway in kidney cells (13). Therefore, we investigated the effect of combination therapy on ERK1/2 pathway. As shown in Fig. 4A and B, the combination treatment group significantly reduced Ras/Raf/MEK/ERK1/2 pathway activity in 786-O cells compared with YS-1 or ADM monotherapy treatment group. Furthermore, the mRNA levels of ERK1 and ERK2 were slightly decreased when YS-1 was combined with ADM (Fig. 4C). The combination treatment reduced phosphorylated ERK1/2. However, it is not clear to which drug (or both) the function is due. Thus, we measured the effect of YS-1 and ADM separately on p-ERK1/2 in 786-O cells. As shown in Fig. 4D, a decrease in the expression of p-ERK1/2 as well as Notch1 was observed after 786-O cells were treated with YS-1 for $6 \mathrm{~h}$; similarly, the expression of p-ERK1/2 was significantly increased after treatment of 786-O cells with ADM alone for $6 \mathrm{~h}$. These results indicated that YS-1 promoted ERK1/2 inactivation through regulating Notch1 pathway, and YS-1 combined with ADM exerts its 

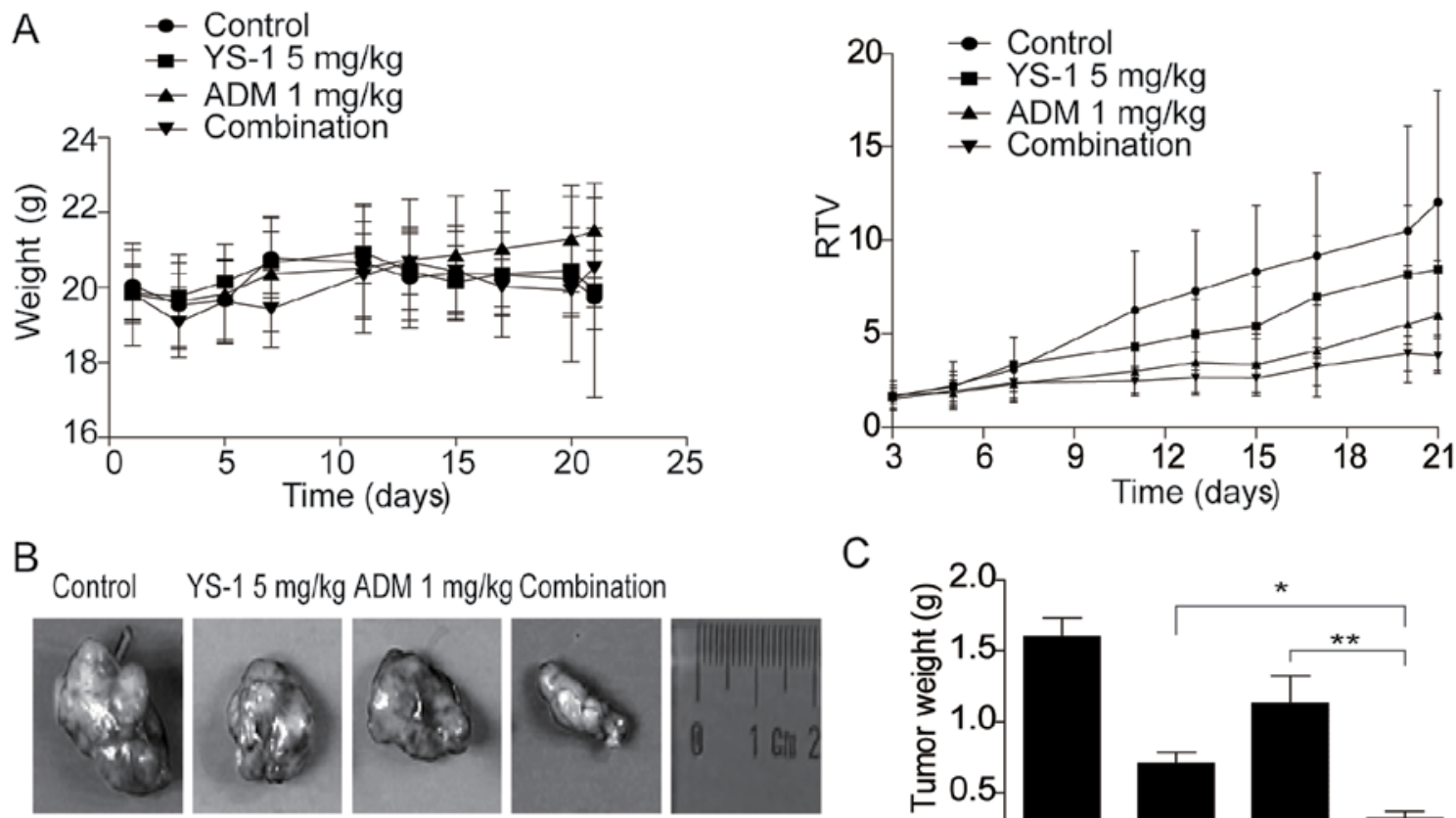

YS-1 $5 \mathrm{mg} / \mathrm{kg}$ ADM $1 \mathrm{mg} / \mathrm{kg}$ Combination
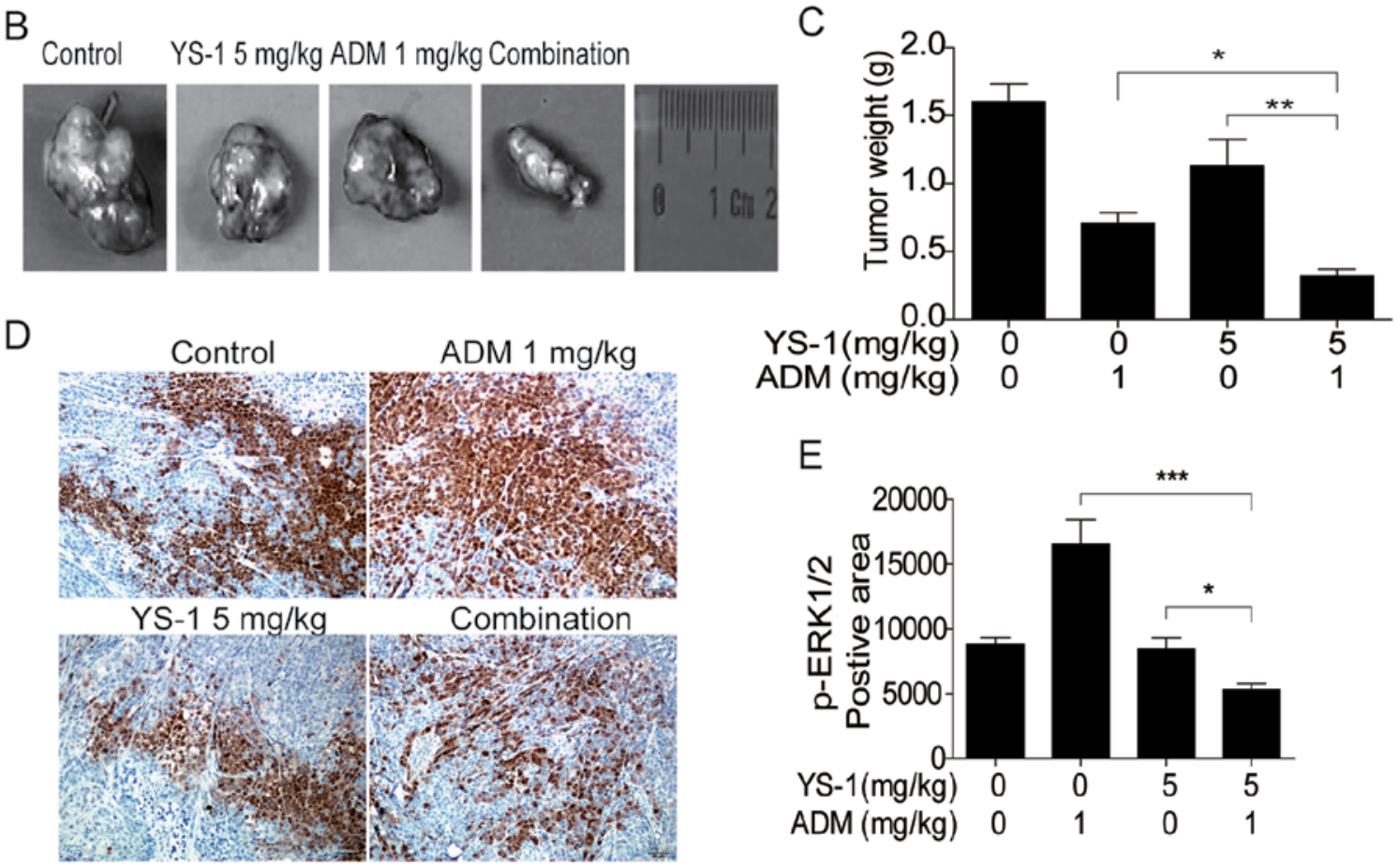

Figure 6. Combination treatment and inhibition of tumor growth in 786-O xenograft nude mice. (A) The animal weight and RTV were examined in vivo. (B) Representative photographs of tumors, respectively, in each group at the end of the experiment. (C) The statistical graph of tumor weight when YS-1 combined with ADM. (D and E) Tumor tissues from 786-O-xenografted nude mice after YS-1/ADM combination treatment were analyzed by immunohistochemistry staining of $\mathrm{p}$-ERK1/2. Statistical analysis was performed using one-way ANOVA followed by Bonferroni's multiple comparison test, "P $<0.05$; ${ }^{* *} \mathrm{P}<0.01 ;{ }^{* * *} \mathrm{P}<0.001$.

anti-proliferative activity via inhibiting the activation of ERK1/2 pathway.

YS-1 combined with ADM exerted synergistic effects through $p$-ERK1/2 inhibition. To confirm the involvement of p-ERK1/2 in the inhibition of proliferation by YS-1 combined with ADM, we knocked down ERK1/2 by using ERK1/2 siRNA. The ERK1/2 and p-ERK1/2 levels of 786-O cells were decreased remarkably (Fig. 5A). Then we examined the anti-proliferative effect of YS-1 combined with ADM on ERK1/2 knockdown 786-O cells, data showed that the combination treatment could not induce cell cycle arrest (Fig. 5B), and could not inhibit the clone ability of 786-O cells (Fig. 5C and D). These data confirmed that YS-1 combined with ADM exerted synergistic effects through $\mathrm{p}-\mathrm{ERK} 1 / 2$ inhibition.

Combination treatment inhibits tumor growth in 786-O-xenografted nude mice. To assess the efficiency of combination therapy YS-1 and ADM in vivo, we established the 786-O cell xenograft model and evaluated the RTV and ERK1/2 activation. As shown in Fig. 6A, the value of RTV was decreased in the combination group, without showing any obvious toxic effect. Results showed that $5 \mathrm{mg} / \mathrm{kg}$ YS-1 combined with $1 \mathrm{mg} /$ $\mathrm{kg}$ ADM exerted a significant synergistic inhibitory effect on 786-O xenografts (Fig. 6B and C). In tumor tissues from the 786-O-xenografted nude mice treated with YS-1/ADM combination, the positive areas for $\mathrm{p}-\mathrm{ERK} 1 / 2$ were reduced significantly (Fig. 6D and E). These results suggested that YS-1 combined with ADM boosted the anti-proliferative effect in vivo via p-ERK1/2 inhibition, which was consistent with the in vitro data.

\section{Discussion}

In the present investigation, we demonstrated that p-ERK1/2 was involved in the chemoresistance to ADM in RCC cells; 
ADM monotherapy caused renal toxicity by promoting the activation of ERK1/2 in kidney cells. We found that YS-1, a recombinant human $\mathrm{p} 43$ protein, could increase the sensitivity of 786-O cells to ADM by inhibiting the p-ERK1/2 level in 786-O cells. YS-1 promoted ERK1/2 inactivation through regulating the Notch1 pathway. By using ERK1/2 siRNA, we found the synergistic anti-proliferative effect of YS-1 combined with ADM was reversed. In 786-O cell xenograft model, we also found a significantly synergistic inhibitory effect on 786-O xenografts when $5 \mathrm{mg} / \mathrm{kg}$ YS-1 was combined with $1 \mathrm{mg} / \mathrm{kg}$ ADM. These findings suggested that YS-1 might synergistically combine with ADM to inhibit the RCCs through decreasing p-ERK1/2 modulation of EGFR downstream signaling.

As an important adjuvant treatment, chemotherapy serves as a necessary component of postoperative therapy for renal cancer (25). However, most traditional chemotherapeutic drugs lead to drug resistance and this has become a major obstacle in chemotherapy (26). Therefore, it is imperative to identify novel therapeutic targets which are involved in the acquisition of drug resistance.

Because of the advantages of combination with low toxicity, high efficiency, there have been many studies on the combined application of vascular inhibitors and cytotoxic drugs, such as: Combination of TNP-470 and mitomycin C (MMC), ADM, cisplatin, gemcitabine and 5-fluorouracil (5-FU) in nude mouse xenograft model, which significantly increased its antitumor activity (27-29); Doxorubicin with sorafenib augments cytotoxicity to RCC through p-ERK1/2 inhibition, this opposite response of p-eIF $2 \alpha$ to sorafenib treatment may determine cell fate after sorafenib administration because increases of p-ERK1/2 and p-eIF2 $\alpha$ can rescue cell death (30). In addition, some anticancer agents combined with anti-angiogenic drugs could improve therapeutic index through their anti-angiogenic effects (31). As shown in the mouse model, doxorubicin combined with anti-VEGFR2 antibody exerted an excellent therapeutic effect (32), YS-1 plus ADM might be another novel method in terms of antiangiogenic therapeutics.

However, further investigation of the effect of the YS-1 and ADM combination in clinical trials is necessary to confirm the promising in vitro and in vivo results reported here.

\section{Acknowledgements}

This work was financially supported by the National Natural Science Foundation of China $(81573456,81302794)$ and the National High Technology Research and Development Program of China (2014AA022208). We are highly thankful to both organizations for this sponsorship.

\section{References}

1. Guo H, German P, Bai S, Barnes S, Guo W, Qi X, Lou H, Liang J, Jonasch E, Mills GB, et al: The PI3K/AKT pathway and renal cell carcinoma. J Genet Genomics 42: 343-353, 2015.

2. Jemal A, Siegel R, Ward E, Murray T, Xu J, Smigal C and Thun MJ: Cancer statistics, 2006. CA Cancer J Clin 56: 106-130, 2006.

3. Breda A, Lucarelli G, Rodriguez-Faba O, Guirado L, Facundo C, Bettocchi C, Gesualdo L, Castellano G, Grandaliano G, Battaglia M, et al: Clinical and pathological outcomes of renal cell carcinoma (RCC) in native kidneys of patients with end-stage renal disease: A long-term comparative retrospective study with RCC diagnosed in the general population. World J Urol 33: 1-7, 2015.
4. Bangalore N, Bhargava P, Hawkins MJ and Bhargava P: Sustained response of sarcomatoid renal-cell carcinoma to MAID chemotherapy: Case report and review of the literature. Ann Oncol 12: 271-274, 2001.

5. Sun W, Kalen AL, Smith BJ, Cullen JJ and Oberley LW: Enhancing the antitumor activity of adriamycin and ionizing radiation. Cancer Res 69: 4294-4300, 2009.

6. Granados-Principal S, Quiles JL, Ramirez-Tortosa CL, SanchezRovira P and Ramirez-Tortosa MC: New advances in molecular mechanisms and the prevention of adriamycin toxicity by antioxidant nutrients. Food Chem Toxicol 48: 1425-1438, 2010.

7. Diaz RR, Kwon JK, Lee JY, Nahm JH, Cho KS, Ham WS, Cho NH and Choi YD: Renal pelvic urothelial carcinoma with vena caval thrombus mimicking renal cell carcinoma. Korean J Urol 55: 624-627, 2014

8. Wu XX, Zeng Y, Jin XH and Kakehi Y: Enhanced susceptibility of adriamycin-treated human renal cell carcinoma cells to lysis by peripheral blood lymphocytes and tumor infiltrating lymphocytes. Oncol Rep 18: 353-359, 2007.

9. Milner LS, Wei SH and Houser MT: Amelioration of glomerular injury in doxorubicin hydrochloride nephrosis by dimethylthiourea. J Lab Clin Med 118: 427-434, 1991.

10. Kojima S, Icho T, Hayashi M, Kajiwara Y, Kitabatake K and Kubota K: Inhibitory effect of 5,6,7,8-tetrahydroneopterin on adriamycin-induced cardiotoxicity. J Pharmacol Exp Ther 266: 1699-1704, 1993

11. Lee YS, Han JM, Kang T, Park YI, Kim HM and Kim S: Antitumor activity of the novel human cytokine AIMP1 in an in vivo tumor model. Mol Cells 21: 213-217, 2006.

12. Sun L, Yang Q, Wang P, Liu D, Liang W, Lin S and Yuan S: The influence of YS-1 on the Dl14-Notch1 signaling pathway. Acta Biochim Biophys Sin (Shanghai) 46: 56-64, 2014.

13. Park EJ, Kwon HK, Choi YM, Shin HJ and Choi S: Doxorubicin induces cytotoxicity through upregulation of pERK-dependent ATF3. PLoS One 7: e44990, 2012.

14. Deschênes-Simard X, Kottakis F, Meloche S and Ferbeyre G: ERKs in cancer: Friends or foes? Cancer Res 74: 412-419, 2014.

15. Collisson EA, Trejo CL, Silva JM, Gu S, Korkola JE, Heiser LM, Charles RP, Rabinovich BA, Hann B, Dankort D, et al: A central role for $\mathrm{RAF} \rightarrow \mathrm{MEK} \rightarrow \mathrm{ERK}$ signaling in the genesis of pancreatic ductal adenocarcinoma. Cancer Discov 2: 685-693, 2012.

16. Kisucká J, Barancík M, Bohácová V and Breier A: Reversal effect of specific inhibitors of extracellular-signal regulated protein kinase pathway on P-glycoprotein mediated vincristine resistance of L1210 cells. Gen Physiol Biophys 20: 439-444, 2001.

17. Lin JC, Chang SY, Hsieh DS, Lee CF and Yu DS: Modulation of mitogen-activated protein kinase cascades by differentiation-1 protein: Acquired drug resistance of hormone independent prostate cancer cells. J Urol 174: 2022-2026, 2005.

18. Steelman LS, Abrams SL, Shelton JG, Chappell WH, Bäsecke J, Stivala F, Donia M, Nicoletti F, Libra M, Martelli AM, et al: Dominant roles of the Raf/MEK/ERK pathway in cell cycle progression, prevention of apoptosis and sensitivity to chemotherapeutic drugs. Cell Cycle 9: 1629-1638, 2010.

19. McCubrey JA, Steelman LS, Chappell WH, Abrams SL, Franklin RA, Montalto G, Cervello M, Libra M, Candido S, Malaponte G, et al: Ras/Raf/MEK/ERK and PI3K/PTEN/ $\mathrm{Akt} / \mathrm{mTOR}$ cascade inhibitors: How mutations can result in therapy resistance and how to overcome resistance. Oncotarget 3: 1068-1111, 2012.

20. McCubrey JA, Steelman LS, Chappell WH, Abrams SL, Wong EW, Chang F, Lehmann B, Terrian DM, Milella M, Tafuri A, et al: Roles of the Raf/MEK/ERK pathway in cell growth, malignant transformation and drug resistance. Biochim Biophys Acta 1773: 1263-1284, 2007.

21. McCubrey JA, Steelman LS, Abrams SL, Lee JT, Chang F, Bertrand FE, Navolanic PM, Terrian DM, Franklin RA, D'Assoro AB, et al: Roles of the RAF/MEK/ERK and PI3K/ PTEN/AKT pathways in malignant transformation and drug resistance. Adv Enzyme Regul 46: 249-279, 2006.

22. Gebäck T, Schulz MM, Koumoutsakos P and Detmar M: TScratch: A novel and simple software tool for automated analysis of monolayer wound healing assays. Biotechniques 46: 265-274, 2009

23. Zhao R, Sun L, Lin S, Bai X, Yu B, Yuan S and Zhang L: The saponin monomer of dwarf lilyturf tuber, DT-13, inhibits angiogenesis under hypoxia and normoxia via multi-targeting activity. Oncol Rep 29: 1379-1386, 2013. 
24. Kalimuthu S and Se-Kwon K: Cell survival and apoptosis signaling as therapeutic target for cancer: Marine bioactive compounds. Int J Mol Sci 14: 2334-2354, 2013.

25. Yoon EL, Yeon JE, Lee HJ, Suh SJ, Lee SJ, Kang SH, Kang K, Yoo YJ, Kim JH, Yim HJ, et al: Systemic cytotoxic chemotherapy of patients with advanced hepatocellular carcinoma in the era of sorafenib nonavailability. J Clin Gastroenterol 48: e22-e29, 2014.

26. Brown R, Curry E, Magnani L, Wilhelm-Benartzi CS and Borley J: Poised epigenetic states and acquired drug resistance in cancer. Nat Rev Cancer 14: 747-753, 2014.

27. Kato T, Sato K, Kakinuma H and Matsuda Y: Enhanced suppression of tumor growth by combination of angiogenesis inhibitor O-(chloroacetyl-carbamoyl)fumagillol (TNP-470) and cytotoxic agents in mice. Cancer Res 54: 5143-5147, 1994.

28. Saijo N and Kenmotsu H: Recent development of moleculartargeted drugs in lung cancer. Intern Med 49: 1923-1934, 2010.
29. Jia L, Zhang MH, Yuan SZ and Huang WG: Antiangiogenic therapy for human pancreatic carcinoma xenografts in nude mice. World J Gastroenterol 11: 447-450, 2005

30. Shiota M,Eto M, Yokomizo A, Tada Y, Takeuchi A, Masubuchi D, Inokuchi J, Tatsugami K, Kuroiwa K, Uchiumi T, et al: Sorafenib with doxorubicin augments cytotoxicity to renal cell cancer through PERK inhibition. Int J Oncol 36: 1521-1531, 2010.

31. El-Kenawi AE and El-Remessy AB: Angiogenesis inhibitors in cancer therapy: Mechanistic perspective on classification and treatment rationales. Br J Pharmacol 170: 712-729, 2013.

32. Zhang L, Hannay JA, Liu J, Das P, Zhan M, Nguyen T, Hicklin DJ, Yu D, Pollock RE and Lev D: Vascular endothelial growth factor overexpression by soft tissue sarcoma cells: Implications for tumor growth, metastasis, and chemoresistance. Cancer Res 66: 8770-8778, 2006. 